\title{
Physical protection systems of nuclear facilities: a proposed nuclear power plant general layout and regulatory requirement
}

\author{
Olivea A. Elhefnawy* and \\ Mahmoud F. Barakat
}

Egyptian Nuclear and Radiological Regulatory Authority (ENRRA), 3 Ahmed Elzomer st, Nasr City 11762, PO Box 7551, Cairo, Egypt

Email: oliveaeaea@yahoo.com

Email: mbarakat49@yahoo.com

*Corresponding author

\begin{abstract}
At present, great efforts in Egypt are directed towards elaborate physical protection regulations to protect nuclear and radiological facilities from any adversary actions, especially after signing the agreement between Egypt and Russia for the establishment of the first Egyptian nuclear power plant in Dabaa. The upcoming regulations will include a physical protection regulation of nuclear facilities and nuclear materials. Thus, the present work is concerned with a proposal of physical protection regulation of nuclear facilities. This proposal discusses the role of the licensee in defining threat assessment and design basis threat followed by classifying different areas in general layout of nuclear facility or nuclear power plant. Also, the requirements of an efficient physical protection system are discussed based on the four basic elements, i.e. entry control, intrusion detection, delay of intruder, and response force. This suggested regulation takes into consideration the International Atomic Energy Agency recommendations and many other countries' regulations.
\end{abstract}

Keywords: physical protection systems; nuclear facilities; nuclear power plant; general layout; threat assessment; design basis threat; regulatory requirements; entry control; intrusion detection; delay of intruder; response force.

Reference to this paper should be made as follows: Elhefnawy, O.A. and Barakat M.F. (2019) 'Physical protection systems of nuclear facilities: a proposed nuclear power plant general layout and regulatory requirement', Int. J. Nuclear Safety and Security, Vol. 1, No. 1, pp.18-30.

Biographical notes: Olivea A. Elhefnawy graduated from the Chemistry Department, Faculty of Science, Al-Azhar University in 2004. She got MSc in Organic Chemistry from El Azhar University in 2009 and $\mathrm{PhD}$ in Inorganic and Analytical Chemistry from Ain Shams University in 2013. Her main fields of activities are in analytical chemistry especially in separation of nuclear materials by using nano-sized materials either by using batch or column techniques; qualitative and quantitative nuclear material determination by using different techniques (EDX, UV-vis, ICP-OES); synthesis and characterisation of different materials (complexes, inorganic, modified materials, and nanomaterials). Also she has a good experience in nuclear security and physical protection designs for nuclear and radioactive facilities. She is working as a 
Lecturer in Nuclear Safeguards and Physical Protection Department in Egyptian Nuclear and Radiological Regulatory Authority (ENRRA) from 2013-until now. She is providing technical support to the regulatory body in ENRRA.

Mahmoud F. Barakat graduated from the Chemistry Department, Faculty of Science, Cairo University in 1956. He got his $\mathrm{PhD}$ at Moscow State University in 1963 in Radiochemistry and subsequently worked as an Assistant Professor (1963), Associated Professor (1970) and Professor of Nuclear and Radiochemistry in the Atomic Energy Authority of Egypt, His main field of activities are chemistry of nuclear transformations, counting systems for lowenergy beta emitter, radio-photosynthesis, radiation protection and radiation safety, nuclear regulations and environmental radioactivity control. He actively participated in the foundation of the National Centre of Nuclear Safety and Radiation Control and was its chairman during 1990-1993. He was selected as Director General of the Arab Atomic Energy Agency and worked in the post from 1993 until 2001. He worked as a consultant to the president of the Atomic Energy Authority in Nuclear Safety from 2001 until 2013. Now he is working as a Consultant to the President of the Nuclear and Radiological Regulatory Authority.

This paper is a revised and expanded version of a paper entitled 'Physical protection systems of nuclear facilities: a proposed nuclear power plant general layout and regulatory requirement' presented at the 'International Conference on Nuclear Security: Commitments and Actions', Vienna, Austria, 5-9 December 2016.

\section{Introduction}

Egypt issued the legal basis for developing regulations in Law No. 7/2010 entitled "The Law for Regulating Nuclear and Radiological Activities". According to that Law, a nuclear security regime has to be established in order to protect nuclear facilities and nuclear activities for peaceful purposes, against malicious acts either theft or sabotage. The article 17 of the Law No. 7/2010 provides "A Nuclear and Radiological Regulatory Authority (ENRRA) has to be established as an independent authority under the Prime Minister of Egypt to control all nuclear facilities and radiological activities in the country, the structure of ENRRA was described in Figure 1. Therefore, ENRRA is empowered to implement the necessary administrative and technical measures in order to strengthen the physical protection of nuclear materials, radioactive materials and radioactive sources in use, storage or during transportation according to article 77 of the Law [Egyptian Law No. (7/2010)]. ENRRA involved in the following activities:

1 Preparation of nuclear security regulations on physical protection of nuclear and radioactive materials and facilities.

2 Manpower development and building the infrastructure necessary for carrying out all regulatory duties in the country as well as duties to be performed, during construction and operation of the nuclear facilities.

Among these duties, establishing the nuclear security regulations in Egypt was become essential, especially after signing the agreement between the governments of Egypt and Russia for establishing the first Egyptian Nuclear Power Plant (ENPP) in Dabaa. 
Figure 1 The organisational structure of ENRRA

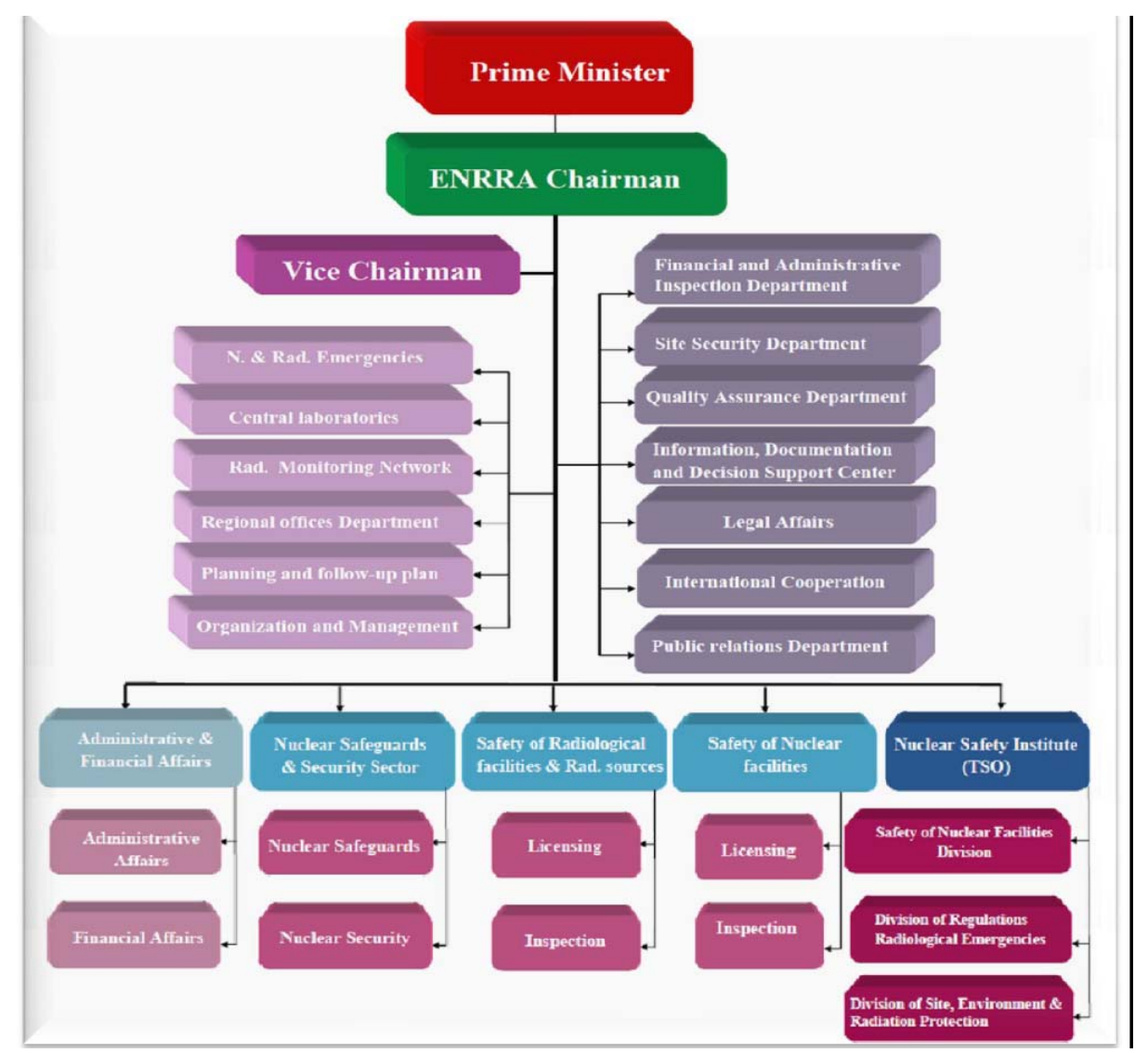

Dabaa is a city in Matrouh Governorate, north-western Egypt. It lies on the coats of the Mediterranean Sea, and that was the main reason for selecting Dabaa as the site to build the first ENPP. The location of Dabaa is shown in Figure 2.

Figure 2 Location of Dabaa in Egypt

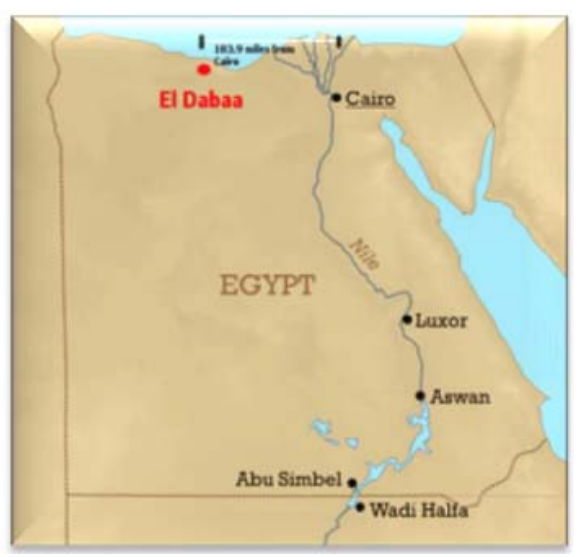


The nuclear power plant will include four nuclear reactors of the third generation pressurised water reactor of VVER-1200 type, with total capacity $4800 \mathrm{MW}$ as shown in Figure 3. The establishment of the first two reactors is proposed to be completed before 2025, starting from the implementation date, followed by operating the third unit after a year, then a year later the operation of fourth and final unit (http://www.sis.gov.eg).

Figure 3 The design of the Egyptian NPP in Dabaa by the Russian company "Rosatom"

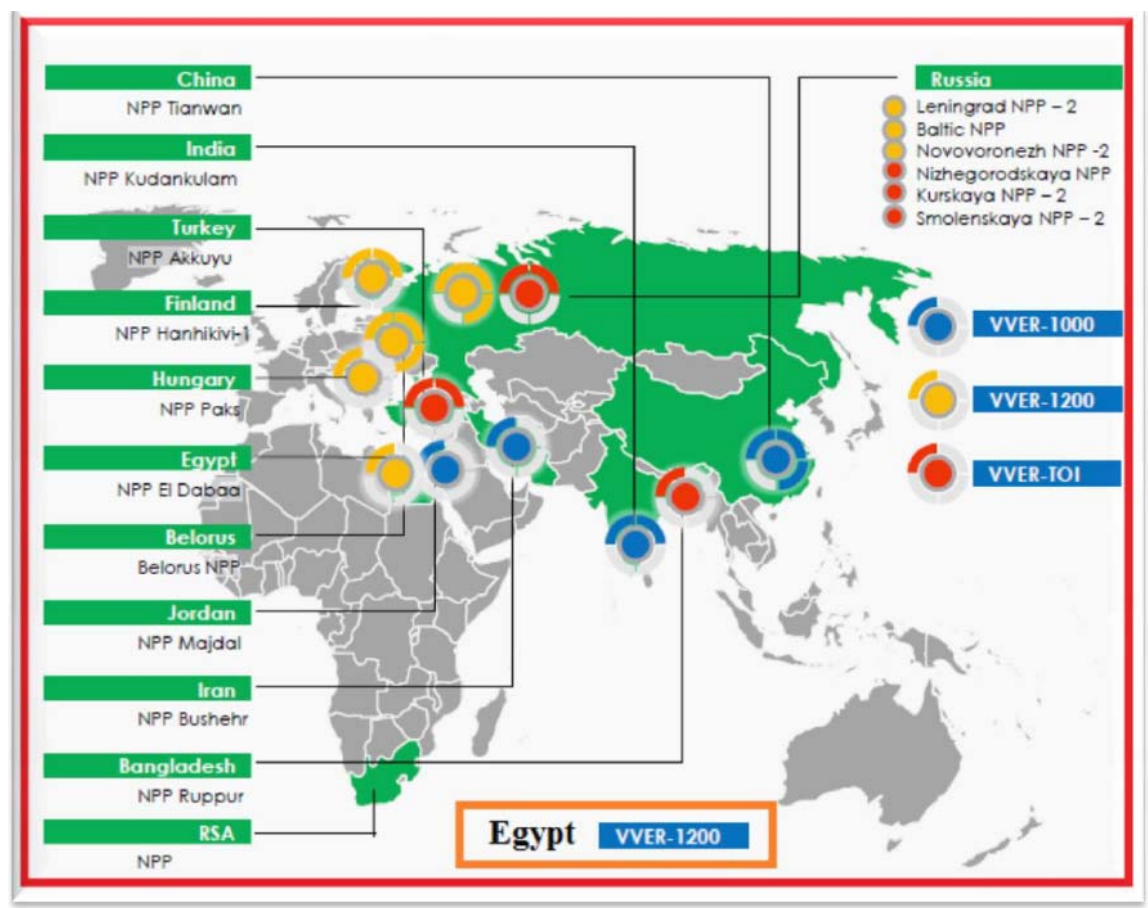

Egypt after the launch of this project enters officially the peaceful uses of nuclear energy era. According to this approach ENRRA tries to get ready through organising the State's legislative framework on nuclear security regime. Therefore, ENRRA organised a workshop in Cairo (11-13 March, 2014) on "Nuclear Security Regulations". This workshop concluded with: ENRRA proposed to issue the following regulation topics over the next few years:

1 Physical protection of nuclear facilities and nuclear materials;

2 Security for handling and disposal of radioactive sources;

3 Physical protection of radiological facilities; and

4 Security for transport of nuclear and other radioactive materials and on the import and export of radioactive sources (ENRRA Workshop, 2014).

The present work is concerned with the regulatory requirements for physical protection of nuclear facilities which are generally compatible with the IAEA nuclear security recommendations on physical protection of nuclear facilities (NSS No. 10; NSS No. 13; NSS No. 16; NSS No. 20; Physical Security Handbook, 2013) taking into consideration 
many examples of physical protection regulations of other countries (Canada regulation, 2013; Turkish Regulation, 1982; U.S.NRC Regulations, 2014; U.S.NRC Regulations, 1979; UK Regulations, 2013).

\section{Physical protection regulatory requirements}

In order to define and formulate a regulatory requirements in physical protection of nuclear facilities, ENRRA needs to establish effective interactions, contacts and co-operations with other regulatory bodies and organisations within the State and outside (e.g. IAEA) to establish clear regulatory vision, and to help in producing appropriate regulatory equipment's combatable with the international standards in physical protection of nuclear facilities (NSS No. 10; NSS No. 13; NSS No. 16; NSS No. 20; Physical Security Handbook, 2013). Physical protection regulation should address explicitly the possibilities of unauthorised access of adversaries with malevolent intention to theft or sabotage nuclear facilities. Physical protection regulation of nuclear facilities helps the licensee to design, modify and evaluate the physical protection system of the nuclear facility according to the requirements issued by the competent authority (ENRRA). To design an efficient physical protection system of nuclear facility, first it is necessary to identify the various potential threats facing the facility, then to assess these threats (NSS No. 10). These threats will be used in establishing the Design Basis Threat (DBT) which is the basis for designing the physical protection system. Those are the corner stone in designing any physical protection system of nuclear facility (NSS No. 10).

\section{Threat Assessment (TA)}

Facility-threat assessment is an evaluation of the threats based on the available sources of information that describe the motivations, intentions, and capabilities of adversaries (NSS No. 10). The licensee shall take into account the following activities towards facility-threat assessment:

- The licensee shall cooperate with the competent authority and other stakeholders in gathering information to assess threats and update this threat assessment once every five years at least, in order to ensure sustainability of the facility-threat assessment.

- Modifying the physical protection system of the facility, if necessary, to counteract any credible threat as a result of the TA.

- Keeping a written record of each threat assessment process in special record.

The licensee is allowed to make adjustment to the physical protection system of the nuclear facility only after the prior approval of ENRRA with explanation of the reason for these amendments.

\section{Design basis threat (DBT)}

DBT is used to design and evaluate the physical protection system based on threat assessment against any malicious acts either unauthorised removal or sabotage (NSS No. 10). The licensee shall take into consideration the following points in establishing the DBT: 
- The licensee in cooperation with the competent authority shall establish DBT analysis based on threat assessment followed by ENRRA approval.

The licensee shall revise and update the DBT in case of any extraordinary event occurring in the facility or at least once every five years, to ensure sustainable effectiveness of the applied physical protection system (NSS No. 10; Canada regulation, 2013; U.S.NRC Regulations, 1979).

\section{The physical protection system of the nuclear facility}

The physical protection system is a collection of measures for protecting nuclear facilities and nuclear materials against sabotage, theft, diversion, and any other malicious acts according to the required level of protection. There are four basic elements in any physical protection system of nuclear facilities (Physical Security Handbook, 2013):

- Entry control;

- Intrusion detection;

- Delaying of the intruder; and

- Response force

These elements should be present in any effective physical protection system to achieve the high level of protection against the expected adversary action. The main target of physical protection system is to protect nuclear facility from any malicious acts. Therefore, nuclear facility shall be defined, described, and classified areas from the boundary layer to the central area according to the operational activities in the nuclear facility. The areas inside the boundary layer usually termed site layout. The licensee shall describe all information about facility layout e.g. nuclear materials handled, used or stored, also all measures and components which required forming the physical protection system of nuclear facility.

\section{General description of nuclear facility with a NPP layout}

The licensee shall prepare a general description of the nuclear facility layout by defining all areas and their specification according to the regulatory requirement for designing an efficient physical protection system (Physical Security Handbook, 2013). The site of any nuclear facility is surrounded by the perimeter fence, which called limited access area perimeter. The area directly inside the perimeter fence is called "limited access area". The protected area is inside the limited access area and also surrounded by a perimeter fence, which shall be a double fence in case of NPP and nuclear complexes as explained later. Inner and vital areas are located inside the protected area. They are usually containing the strategic parts of the nuclear facility (e.g. nuclear reactor, nuclear materials storage etc.). Therefore, intruder has to overcome at least four perimeter fences to reach the vital or inner area in the NPP for example, first limited access area perimeter, protected area double fence and finally the vital or inner area perimeter (see Figure 4). More than one vital or inner area may be located within the same 
protected area, but each of them shall have a separate perimeter. Also more than one protected area may be located in the same limited access area in the site with a separate protected area perimeter.

Figure 4 General NPP layout

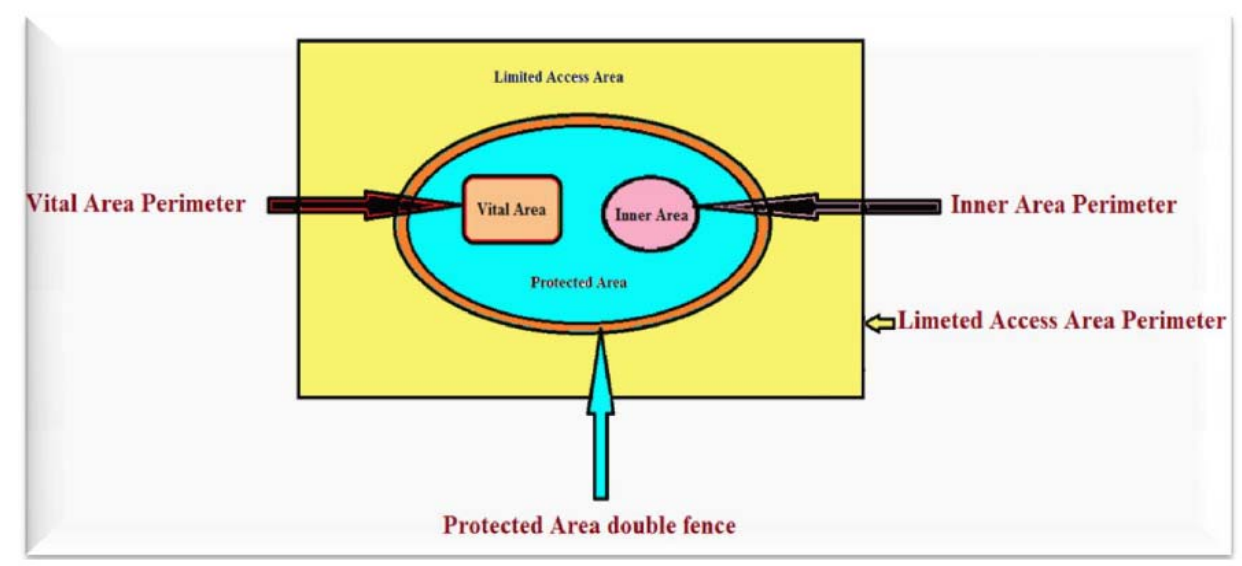

\subsection{Limited access area (LAA)}

Limited access area: In the nuclear facility site may be contains one or more protected areas, in which category III nuclear materials are handled, used or stored (NSS No. 13). The licensee shall identify the dimensions of the LAA in the physical protection plan of the facility.

\section{Entry control in the LAA}

- LAA shall contain separate gates for persons and vehicles; each gate contains checkpoints for individuals, vehicles and packages entering or exiting from the facility.

- The LAA shall be equipped with portals for persons or workers that are equipped with a sufficient entry control equipment's and sensors such as; card reader, finger print system, voice detection or any related sensors, and kept under direct surveillance by a nuclear security officer.

Intrusion detection in the LAA

- LAA shall be equipped with suitable intrusion detection sensors, which are distributed on the LAA perimeter fence such as: active infrared, infrasonic, electric field, radiation, and microwave sensors etc., to detect any unauthorised attacks over the LAA perimeter fence.

- Continuous surveillance and assessment systems like cameras shall be used to follow and assess the current situation, the actions and the movement of offenders. All records shall be conveyed to the nuclear security officer and kept available to the administration. 
Delay of the intruder in the LAA

- The LAA shall be surrounded by a physical barrier which shall be in the form of a fence of suitable height. The fence may be constructed of concrete, steel net or composites or any other materials that can provide the same level of protection, and preferred to be topped with barbed wire layers, the same specification can be applied in the construction of the protected area perimeter.

- Physical barriers such as boundaries, gates, walls, doors, locks, barbed wire, fences and other types of perimeter security barriers can provide adequate delay of intruder in the LAA.

Response force in the $L A A$

- Guards and other assistive tools, for example guards equipped with watchdogs are used as a response force whenever necessary.

\subsection{Protected area}

Protected area is located inside a LAA containing Category I or II of nuclear materials. It shall be surrounded by protected area perimeter with additional physical protection measures (NSS No. 13; Physical Security Handbook, 2013). The licensee shall identify the protected area in the physical protection plan.

Protected area perimeter shall contain separate gates for persons and vehicles, each gate, door or other means of entry or exit shall be kept closed and locked except when persons or land vehicles are entering or exiting (NSS No. 13; Canada Regulation, 2013).

\section{Entry control in the protected area}

- Protected area shall be equipped with a limited number of entrance points with separate gates for persons, vehicle and packages, each entering and exiting gate shall be subjected to inspection under direct continuous surveillance for preventing or minimising any malicious acts against the nuclear facility.

- Entry of vehicles shall be limited to specific parking areas. Every licensee shall implement suitable physical protection measures to avoid the risk of forced vehicles penetration into the protected area.

- $\quad$ Protected area shall contain effective access control measures, which shall be limited to persons who are subjected to trustworthiness evaluation and have an authorised access like passes or badges that must be displayed clearly during existing in the protected area. All access point shall be appropriately secured and fitted with alarm.

- Visitors and temporary workers like maintenance and construction workers who require entry into the protected area shall be always escorted by authorised person.

Detailed records shall be kept for all persons who have any type of access control measures like keys, key cards and/or any electronic systems used to access the protected area (Canada Regulation, 2013; Turkish Regulation, 1982; U.S.NRC Regulations, 2014; U.S.NRC Regulations, 1979; UK Regulations, 2013). 


\section{Intrusion detection in the protected area}

- Protected area shall be supplied with visual continuous surveillance for immediate alarm assessment.

- $\quad$ Protected area shall be equipped with two independent intrusion detection systems. Alarms generated by the intrusion detection system shall be assessed promptly and carefully and appropriate action shall be taken.

- Protected area shall contain Central Alarm Station (CAS) with monitoring equipment's and procedures for alarm assessment to initiate appropriate response actions.

Delay of the intruder in the protected area

- $\quad$ Protected area shall be surrounded by a protected area perimeter fence which may be a separate perimeter fence or building walls depending on the type of the facility.

- In case of the NPP and nuclear complex (nuclear complex contains more than one nuclear facility in the same protected area) protected area perimeter fence shall be a double fence in the form of:

○ The exterior and interior fences are constructed in a suitable height and with a specification as expressed in LAA section.

- The separation distance between the two fences shall not be less than $5 \mathrm{~m}$, and shall be equipped with intrusion detection systems that cover all the area together with other assessment devices to detect any unauthorised access. In addition at certain points monitoring towers are placed.

- Entrances and exits shall be secured by gates, doors which are fastened with a sufficient strength that can't be forcefully opened.

- The physical barriers may be constructed of stone, brick, rock block, concrete, steel or any other comparable material with suitable height. They shall provide sufficient delay time to allow an appropriate response time, under all operational conditions. These barriers are important to delay any unauthorised penetration attempts either by entry of unauthorised vehicles or persons into the protected area.

Response force in the protected area

Response force shall provide immediately response capabilities to ensure that the adversary shall be engaged and impeded until off-site forces arrive particularly, if the in-site forces fail in the confrontation with the adversary.

To achieve this capability a licensee shall:

- Establish a security section with trained and qualified personnel to carry out assigned duties and responsibilities and to apply routine security operations which planned and determined previously, also respond to all emergency situations.

- Establish on-site security guards, police, or other relevant human controls.

The communication tools with the guards shall be ready and available all the time (Canada Regulation, 2013; Turkish Regulation, 1982; U.S.NRC Regulations, 2014; U.S.NRC Regulations, 1979; UK Regulations, 2013). 


\subsection{Inner and vital areas}

Inner area is usually the place where category I of nuclear materials is used and/or stored (NSS No. 13; NSS No. 10; NSS No. 16).

Vital area is containing equipment, systems, devices or nuclear material where sabotage can lead directly or indirectly to high radiological consequences (NSS No. 16).

Every inner and vital area shall be located inside protected area with appropriate additional protection measures. Both inner and vital areas shall be surrounded by additional physical barriers (inner and vital areas perimeter, respectively). The licensee shall identify the inner and vital areas in the physical protection plan of the facility within the following objectives (NSS No. 13)

Inner and Vital areas perimeters shall be designed and constructed to prevent, alone or in combination with other structures, barriers or auxiliary equipment's any unauthorised access or unauthorised removal of nuclear materials. They shall be located at an appropriate distance from each point of the protected area perimeter.

\section{Entry control in the inner and vital areas}

- The number of access points to the inner and vital areas shall be kept to a minimum (ideally only one). Each gate, door, window or other means of access points in the structure or barriers that enclose inner or vital area shall be kept closed and locked. Those barriers can only be unlocked according to an administration declaration and by using two separate access control measures and by applying the two man rule.

- Inner and vital areas shall be kept under direct and continuous visual surveillance by nuclear security officers.

- Persons and packages shall be subject to search on entering and exiting inner and vital areas. The number of authorised persons entering inner and vital areas shall be kept to the minimum and limited to those who have trustworthy persons, in exceptional circumstances and for a limited period.

- Workers are not allowed to enter the inner and vital areas without a written authorisation from the facility manager specifying the reason and the duration of entry.

- A nuclear security officer or physical protection system support person shall be authorised by a written document issued by the facility manager recording the reason and the duration of the entry time.

- Visitors are not authorised to enter without being escorted by an authorised person from the facility.

- Persons who haven't trustworthiness records shall be escorted by Persons having trustworthiness for authorised access.

- Records shall be kept for all persons who enter inner and vital areas or possess keys, keycards and/or other electronic access measures that control access to inner and vital areas.

\section{Intrusion detection in the inner and vital areas}

- All access points shall be appropriately secured and supplied with nuclear material detectors, metal and explosives detectors which shall be promptly and accurately assessed with alarm assessment device in CAS and under direct and continuous monitoring devices, to ensure detection and prevention of unauthorised access. 
- Every inner and vital area shall be equipped with two independent intrusion detection systems with continuous visible and audible alarm devices one of them placed inside the CAS that can be stopped only by a nuclear security officers, and the other in another place outside those areas and can be stopped only by the person authorised to enter inner and vital areas to detect any unauthorised movement inside or outside inner or vital areas, and to detect any tampering that may breach the function of any devices in vital area.

- When nuclear materials are temporarily stored in an unoccupied working area outside inner area, equivalent compensatory physical protection measures shall be established to protect the nuclear materials in this temporarily area.

Delay of the intruder in the inner and vital areas

Inner and vital areas shall be supplied with multiple layers of delay measures, such as locks, windows, walls, distance, serpentine approaches, fences and other types of perimeter security barriers.

- Nuclear materials shall be stored inside inner area in a hardened room ('strong room') or hardened enclosure that provides additional layers of detection and delay against unauthorised access to allow for a timely and appropriate response in case of an unauthorised removal.

- Delay measures shall be designed taking into consideration both "insiders and external adversaries" capabilities, and to be balanced all over the area to avoid any relatively weak spots in all potential points of intrusion.

- Timelines associated with access into the inner and vital areas shall be taken into account when constructing the delay measures which shall be compatible with the response time required to take action against any malicious acts.

Response force in the inner and vital areas

The licensee shall provide and apply a type of response force plans (both physical and tactical response capabilities) to assure that all the capabilities described in the inner and vital areas section are kept safe. Also, the performance plans of the response force shall be frequently tested.

The licensee shall supply the nuclear facility that contains inner or vital areas with an (on- site) security response team which shall be supplied with (NSS No. 13; NSS No. 16; Canada Regulation, 2013; Turkish Regulation, 1982; U.S.NRC Regulations, 2014; U.S.NRC Regulations, 1979; UK Regulations, 2013):

- Equipment for general communication systems such as sirens, duress alarms, and public address systems. These should be timely, accurate and including backup types.

- Personal protection equipment, e.g. gas masks, helmets, body armor, night vision devices and other vision aids.

- A number of different types of vehicles shall be made available to the response force.

- A number of different primary responders to a given threat and a number of secondary responders, if their assistance is required. 
- The licensee shall ensure that the response team has the ability to monitor diversionary tactics and aggressive behaviour and the capable communications to prevent them.

- The Licensee shall ensure that the provided equipment is appropriate for the assigned tasks.

\section{Conclusion}

Egypt starts to implement nuclear security regulations to apply balanced and comprehensive measures of physical protection systems of nuclear and radiological facilities against any unauthorised access or removal of nuclear and radioactive materials. This study is concerned with the development of proposal regulation of physical protection of nuclear facilities. Also it includes general NPP layout with description of its different areas such as: limited access area, protected area, inner and vital areas. The regulatory requirements which are necessary to develop efficient physical protection systems of nuclear facilities were studied. The physical protection system requirements were discussed within the four basic elements: entry controls, intrusion detection, delay of intruder, and response force. All physical protection system requirements shall be applied depending on the threat assessment and DBT as established by the appropriate competent authorities.

\section{References}

Canada Nuclear Security Regulation (2013) Code of Federal Regulation 10, part 51-199, August, 1, 2004.

Egyptian Law No. (2010) Law Regulating Nuclear and Radiation Activities and its Excusive Regulations.

Egyptian Nuclear and Radiological Regulatory Authority (ENRRA) (2014) Outcomes of Drafting Nuclear Security Regulations, ENRRA Workshop, 11-13 March.

International Atomic Energy Agency, Implementing Guide: "Development, Use and Maintenance of the Design Basis Threat" IAEA NSS No. 10, IAEA, Vienna, Austria.

International Atomic Energy Agency, Technical Guidance: "Identification of vital areas at nuclear facilities" IAEA NSS No. 16, IAEA, Vienna, Austria.

International Atomic Energy Agency, Nuclear Security Fundamentals: "Objective and essential elements of a state's nuclear security regime" IAEA NSS No. 20, IAEA, Vienna, Austria.

International Atomic Energy Agency, Nuclear Security Recommendations on Physical Protection of Nuclear Materials and Nuclear Facilities (INFCIRC/225/Revision 5) IAEA NSS No. 13, IAEA, Vienna, Austria.

Physical Security Handbook (2013) 440-2-H Chapter 4 - USGS.

Turkish Regulation (1982) Physical Protection of Nuclear Facilities and Nuclear Materials, July 9, 1982.

U.S.NRC Regulations (1979) Part - 73.45, Performance capabilities for fixed site physical protection systems, November 28, 1979.

U.S.NRC Regulations (2014) Part 73 Physical Protection of Pants and Materials, January 06, 2014.

United Kingdom (UK) (2013) UK Nuclear Industries Security Regulations, April 16, 2013. 


\section{Glossary}

ENRRA: Nuclear and Radiological Regulatory Authority VVER: Water-Water Energetic Reactor

IAEA: International Atomic Energy Agency

NSS: Nuclear Security Series

U.S.NRC: United State Nuclear Regulatory Commission DBT: Design Basis Threat

TA: Threat Assessment

NPP: Nuclear Power Plant

ENPP: Egyptian Nuclear Power Plant

LAA: Limited Access Area

CAS: Central Alarm Station 